resumé alone cannot be an acceptable motive. Many simple clinical projects, and even some complex multicentre ones, fit this category. There is no real thought behind the protocol; often the number of patients studied is too small to be meaningful; analysis of data is appalling; and the discussion is an attempt at rescue.

Why is this so? Probably, most clinicians do not have the scientific training, patience, and discipline necessary to conduct good research. The basic scientist, on the other hand, has no difficulties with the concepts of dose-response curves, randomisation, power analysis, the use of controls, and so on. However, few academic units have the luxury of "their own basic scientist" as part of their unit. Although it is commonplace to assume that anaesthetics departments have an obvious connection with pharmacology, biochemistry, or physiology, in practice such associations are rare between separate entities. The concept of one's own basic scientist was impressed on me by Roy Simpson, the first professor of the anaesthetics unit, who, as one of his first appointments, took on a biochemist. She had no difficulty in pointing out to us fledgling academics that "doctors" had a lot to learn about science. Indeed, in the 27 years since we married, she has never lost this approach, despite my attempts to prove I am a reformed character.

\section{THE SCIENTIST'S PLACE IN CLINICAL RESEARCH}

When I went to head the anaesthetics department in Calgary, Canada, in 1980, I had a good scientist within the department. Sheldon Roth was already a distinguished and senior pharmacologist with his own, established, well funded research programme. He was particularly interested in the effects of toxins, including anaesthetics, on the central nervous system. I sent many young anaesthetists who wanted to do some "proper" research to him. Several could not stand the pace. Sheldon has a robust view of medical doctors - he believes they are underworked, overpaid, and usually idle to boot. However, those who rose to the occasion came out of it better prepared for the rigours of science than other anaesthetists who came ostensibly from a research background.

Returning to this anaesthetics unit in 1990, I persuaded the dean (with some difficulty) that there were enough doctors in the unit and what was needed was a scientist. We advertised with a somewhat confused job description, but essentially seeking a biological scientist, discipline not clearly defined, who wished to work in a clinical department rather than a traditional basic science department. There were a surprising number of applications, but the short list became extremely short once people had visited and discovered that we were not formally linked to any basic science department and that the "basic scientist" would have to function alone and build up from scratch. Jon Stamford on the other hand was a candidate with a gleam in his eyes who could not wait to be "alone" in a clinical department. Soon after his appointment he had his laboratory up and running, had acquired an interest in anaesthesia, and had integrated well with the "doctors" already in the unit. When Christine appeared, I wondered if it was now time for his true purpose to be realised. She seemed keen and was not opposed to going to the laboratory (although she did not seem to see it as quite the unique opportunity I was trying to sell). But the rest, as you have read, is history.

(Accepted 21 November 1995)

\title{
Caring for Older People
}

\section{Community care and social services}

\author{
D Renwick
}

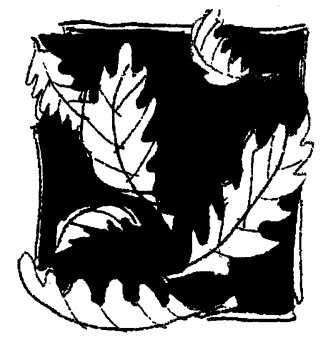

This is the 13th in a series of 14 articles edited by Eileen Burns, Neil Penn, and Graham Mulley

Correspondence to: Dr D Renwick, Department of Medicine for the Elderly, Camborne/Redruth Community Hospital, Redruth, Cornwall TR15 3ER.
The aim of community care is to enable people with various types of disability to live in their own homes, rather than in institutions. This involves the provision of support and services at home by various agencies. After a critical report in 1986 identified problems with coordination and flexibility of community care services, the white paper Caring for People (1989) stated the government's aim to provide a "needs led," responsive range of services, promoting maximum independence of those wishing to live at home rather than enter institutional care. New arrangements were introduced in 1993, involving a formal assessment procedure and the production of a personalised care plan for each individual, incorporating services provided by private and voluntary agencies as well as by social services departments. This article describes the components of community care services supplied by local social services authorities, including housing adaptations, equipment, telephones and alarms, home care, meals, and respite care.

Before April 1993, social services departments had been involved mainly in the provision of care. With the new community care arrangements, social services became responsible for assessing need, designing care plans, and securing delivery of appropriate services.

To increase the spectrum of care available, social services departments were encouraged to purchase care from private and voluntary agencies, thus becoming "enabling authorities" rather than simply providers of care. In addition, financial support for people in residential or nursing homes also became the responsibility of social services departments.

This article describes the community care services supplied by social services departments. Services available from the health authority and from voluntary or private organisations are considered in other articles in this series. ${ }^{12}$ As there is substantial overlap between services provided by these organisations, and as local social services authorities have been encouraged to develop their own arrangements for the provision of community care, organisations providing particular services may vary in different parts of the country.

Entry to the system: the role of the social worker

For both doctors and patients, the key figure in access to community care services is the social worker, who may be based in a hospital medical department for care 
St James's University Trust Hospital, Leeds LS9 7TF

D Renwick, senior registrar of elderly patients or old age psychiatry, in a general practice or health centre, or in the local social services office (social welfare officers or social work assistants have a similar role to that of social workers). Social workers will accept referrals from any source, have information on all services available locally, and act as a liaison between the various agencies involved in the provision of care.

When an individual who may need extra support at home is referred, the social worker will usually start a formal assessment procedure. The complexity of the assessment process varies from an initial assessment of mobility, personal care abilities, current environment, and support network to a more comprehensive process involving input from other members of the interdisciplinary team (including medical staff) and including assessment of finances.

\section{Residential and nursing homes}

Social services departments are responsible for the provision of local authority residential homes, sometimes called aged persons homes or part III homes or, in Scotland, part IV homes. Private residential homes must be registered with the local social services department; the social services inspection and monitoring unit visits them regularly to ensure that standards are maintained (the health authority is responsible for inspecting private nursing homes). Lists of registered private residential and nursing homes are held by social workers in the area. A previous article in this series gives further information about housing for elderly people. ${ }^{3}$

When a comprehensive assessment indicates the need for care in a nursing or residential home, a financial assessment will be performed by social services to identify whether assistance with funding will be offered.

\section{Housing adaptations}

Each social services office has a disability services team made up of community occupational therapists, social workers specialising in physical disability, and rehabilitation officers for visually impaired people. The team deals with applications for home adaptations, including stair lifts or rails, grab rails, bathroom adapta-

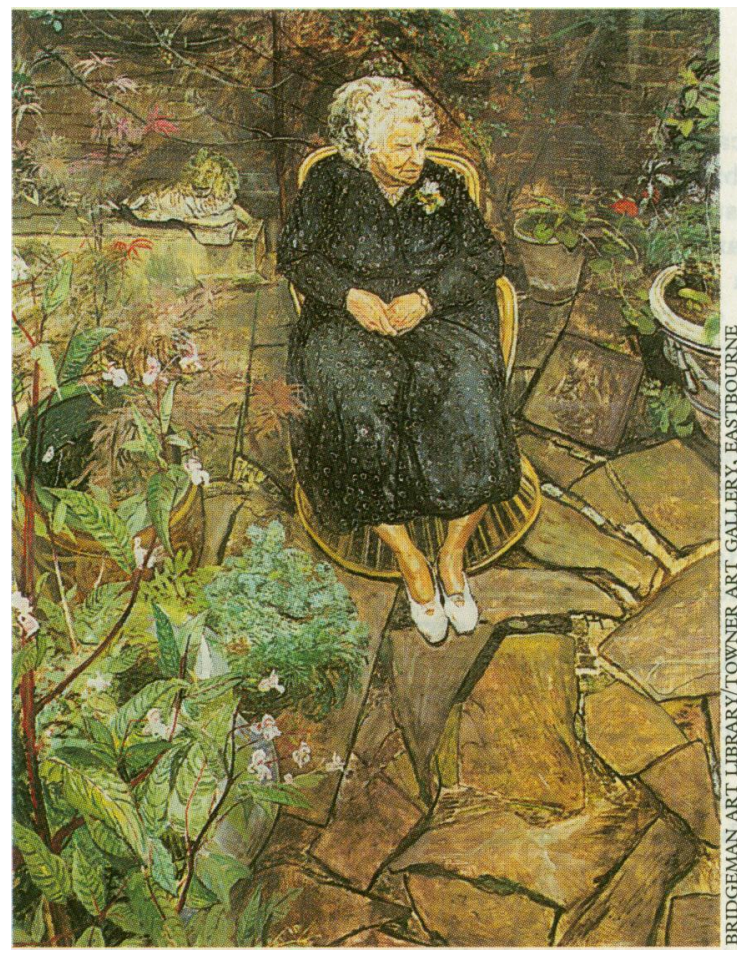

"The old woman in the garden of Number Two" by Carel Weight (1908-92) tions, widening doors for wheelchairs, siting of sockets or switches in convenient positions, and extra heating appliances.

These adaptations will be provided by the social services department if the applicant is physically or mentally disabled or has sensory impairment and if independence or care at home cannot continue, or the applicant will be potentially at risk, without the adaptation. A community occupational therapist will perform a home visit to assess whether the application is appropriate; eligibility for funding will be determined by a financial assessment by social services (see box). For major adaptations (costing more than $£^{500}$ ), a survey by an environmental health officer may be necessary before approval by the housing department.

\section{Funding for adaptations to housing for elderly people}

- Applications for housing adaptations are assessed by the disability services team

- Minor adaptations (costing less than $£ 500$ ) may be provided free of charge to suitable applicants by the social services department

- Major adaptations (costing over $£ 500$ ) to council housing will be funded by the housing department; in some areas tenants may be expected to contribute to the cost

- Private home owners undergo a financial assessment and may be expected to meet a proportion of the costs

\section{Equipment for daily living}

The disability services team can give advice on, assess the need for, and arrange provision of various types of equipment to promote safety and independence in dressing, personal hygiene, using the toilet, cooking and domestic activities, and reaching and lifting. Equipment will be provided if the applicant is physically or mentally disabled, or has sensory impairment, and if assessment by a community occupational therapist indicates that equipment is necessary for maintaining independence or care at home. Separate criteria may exist for the provision of items such as specialised seating, bath lifts, and showers.

Provision of mobility aids (walking sticks and frames) is the responsibility of the health authority and may require assessment by a community physiotherapist. Wheelchairs are provided by the district wheelchair service after assessment by an occupational therapist.

Equipment is usually provided free of charge on permanent loan. Maintenance and repair of equipment and adaptations is generally the responsibility of the user, even when equipment has been supplied by the social services department.

Equipment for nursing needs (mattresses, beds, etc) is supplied by the health authority. What is considered as equipment for daily living and what is deemed nursing equipment varies from area to area.

\section{Telephones}

In certain circumstances, social services departments will contribute to the cost of telephone installation and rental charges (see box).

Special telephone adaptations and equipment are also available from the social services department for people who are unable to use a standard telephone because of disability:

- Partial hearing loss-incoming speech amplifier; volume and pitch control

- Profound deafness-special telephone set

- Sight impairment-large dial ring or buttons; memory buttons

- Inability to hold the handset- "hands free" telephone 


\section{Eligibility for funding for telephone installation and rental}

- Physical or mental disability or sensory impairment - Receiving financial support (income support, housing benefit, etc)

- Living alone or with a carer who could not be expected to deal with an emergency

- At risk unless able to contact helpers in an emergency

- Speech impairment or weak voice-outgoing speech amplifier or speech synthesiser.

The disability services team at the local social services office arranges provision of these specially adapted telephones.

\section{Emergency alarm systems}

In general, 24 hour emergency call systems consist of a press button and loudspeaker installed in the home or a portable pendant button that is worn round the neck or as a bracelet or brooch. A central control centre will contact a nominated carer or the emergency services if the alarm is triggered. Social services departments may provide such systems for people who are elderly or disabled; living alone or with a carer who could not be expected to deal with an emergency; at risk if unable to contact helpers in an emergency; unable to use an ordinary or adapted telephone; or at risk of recurrent falls or collapses.

Applications are assessed by the disability services team. After the financial assessment, a contribution to the cost of the system may be requested.

\section{Home care}

Previously expected only to help with housework and shopping, home care workers ("home helps") now also contribute to aspects of personal care (getting into or out of bed, dressing, washing, toileting) as well as with household tasks, laundry, shopping, and collecting prescriptions or pensions. There is some overlap with the role of community nurses, and responsibility for bathing clients or overseeing medication may vary locally.

Applications for home care are dealt with by the home care manager, who can be contacted through the local social services office. An assessment visit will be performed to determine what input is required, and then a health care worker will be allocated for a number of visits per day or hours per week. The service is available during the daytime seven days a week.

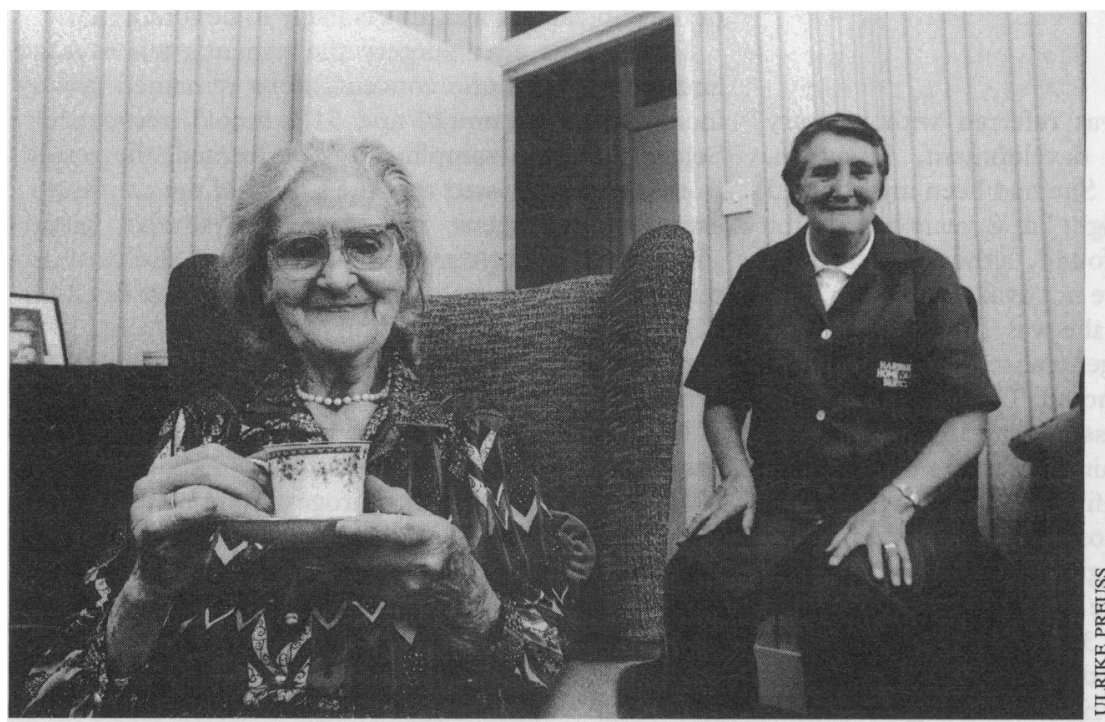

Home care services can improve an elderly person's quality of life
After a financial assessment, a charge is made for the service, and this may vary locally. In some cases, therefore, it is cheaper for the older person to arrange for private help; this also avoids being means tested.

Nursing or supportive care during the night is not provided by social services agencies. Where this is included in a care plan, it will be purchased from a private agency. A financial contribution towards the cost of this may be requested.

\section{Meals}

Social Services departments organise schemes to provide a midday meal to people who are elderly or disabled, are housebound, have no help with shopping or cooking, or would otherwise lack adequate nutrition. These meals are available at low cost, and special diets can be catered for

Meals on wheels-This service delivers a hot cooked meal to the home once daily, up to seven days a week. There is a fixed charge per meal.

Frozen meals - To allow more flexibility, bulk deliveries of precooked frozen meals are also available, with the loan of a freezer for clients who do not own one. Charges are similar to those for meals on wheels.

\section{Respite care}

Respite care aims to ease the pressure on informal carers by substituting an alternative method of care for a period of time-a few hours, a few days, or several weeks. It may be arranged on a "one off" basis or as a regular standing arrangement, for example for two weeks in every two months; the latter may be called "phased" or "intermittent" care.

Sitting service-In some areas, social services departments run schemes where volunteers will "sit" with an elderly person in his or her own home. This provides companionship for elderly people living alone, or gives the carer a break. This service is usually free of charge, although the volunteers will have travel expenses reimbursed.

Day centres may be run by social services or by voluntary organisations. Attendance on one or more days a week provides a break for carers and also support for vulnerable elderly people living alone. Transport and lunch are provided at a small charge. Some day centres have days especially devoted to the care of people with dementia, people of particular ethnic groups, or people with sensory impairment.

Family placement schemes-Many social services departments hold lists of local families who have volunteered to offer respite care for an elderly person. Attempts are made to "match" each client with an appropriate household. A fixed weekly charge is made to the client; the family receives a small payment. This allows people to enjoy a break in a domestic setting rather than have respite in a home.

Respite care in residential or nursing home-Respite care may be arranged in either a local authority residential home or a private residential or nursing home. Some homes have dedicated beds for intermittent care; in others, availability of beds may be a problem. Some offer fixed in-out regimens rather than tailoring the respite to individual needs. Local social services departments may have a "bed bureau" to help in the search for a bed for respite care. A fixed charge is payable for local authority homes; social services may meet a proportion of the cost of intermittent care in a private home, after financial assessment.

"Holidays"-In some areas, social services departments have arrangements with local authority homes in different regions (for example, in a seaside resort) to allow a period of respite care to be taken as a holiday. 
For people who have complex disability or multiple medical problems, respite at a day hospital or in a hospital bed might be more appropriate than care in their own home or a residential home. This can be arranged by the local hospital department of elderly medicine after referral by a general practitioner.

\section{Types of respite care provided by social services departments \\ - Sitting service \\ - Day centre attendance \\ - Family placement schemes \\ - Respite in residential or nursing home}

\section{Services for elderly people with sensory} impairment

Local social services departments hold a register of blind and partially sighted people. Registration is voluntary, and follows referral to and examination by an ophthalmologist

Rehabilitation officers for visually handicapped people work as members of the disability services team and can give advice to help a person with impaired vision cope with the activities of daily living. This may include training in communication methods and techniques to improve mobility, and special equipment (for example clocks, telephones) may be provided.

Social services rehabilitation officers also act as a link with voluntary services for visually impaired or deaf people. Social services departments or voluntary bodies may run day centres for partially sighted or blind people and deaf people; local authority homes that specialise in the care of visually impaired people are found in some areas.

\section{Further reading}

Mandelstam M. How to get equipment for disability. London: Jessica Kingsley and Kogan Page for the Disabled Living Foundation, 1994.

Groves T, ed. Countdown to community care. London: BMJ Publishing, 1993.

Meredith B. The community care handbook. The new system explained. London: Age Concern England, 1993.

I thank Maureen Leahy, John Moore, Liz Ward, and Val Brook for providing me with up to date information for this article.

1 Pushpangadan M, Burns E. Community services: health. BMF 1996;313 805-8.

2 Barodawala S. Community care: the independent sector. $B M F 1996 ; 313$ 740-3.

3 Wanklyn P. Homes and housing for elderly people. BMF 1996;313:218-21.

\title{
Lesson of the Week
}

\section{Adrenal mass with virilisation: importance of endocrine investigation}

\author{
Joohi Nasir, Christopher Walton
}

\section{To prevent unnecessary surgery, all patients with adrenal masses should undergo a full endocrine evaluation irrespective of the apparent hormonal activity of the mass}

\section{The Michael White \\ Diabetes and \\ Endocrinology Centre, \\ Royal Hull Hospitals, Hull \\ HU3 2RW \\ Joohi Nasir, research fellow \\ Christopher Walton, \\ consultant physician \\ Correspondence to: $\mathrm{Dr} J$ \\ Nasir, Department of \\ Endocrinology, \\ Addenbrooke's Hospital, \\ Cambridge CB2 2QQ.}

The combination of virilisation, increased androgen activity, and an adrenal mass on imaging in a female patient suggests a diagnosis of adrenal virilising tumour, for which appropriate treatment is surgical removal. Adrenal "incidentalomas," however, are comparatively common, and this combination of problems can also be due to congenital adrenal hyperplasia. We describe a case of virilisation and left sided adrenal tumour in a 16 year old woman in whom a full endocrinological investigation would have avoided unnecessary surgery.

\section{Case report}

A 16 year old woman was referred with primary amenorrhoea, poor breast development, hirsutism, acne, and excessive sweating. She had been investigated for being "above average height" at 8 years of age, for which no cause had been found, although details of investigations performed were not available.

Examination showed that she was $155 \mathrm{~cm}$ in height. Facial acne, greasy skin, generalised hirsutism and increased muscle bulk were noted. There was no breast development. Her blood pressure was $135 / 80 \mathrm{~mm} \mathrm{Hg}$. The findings on genital examination were not recorded. Chromosomal analysis confirmed a normal female karyotype $(46 \mathrm{XX})$, but testosterone and androstenedione concentrations were greatly increased at 14.0 $\mathrm{nmol} / \mathrm{l}$ (normal female range $0-2.8 \mathrm{nmol} / \mathrm{l}$ ) and 68.8 $\mathrm{nmol} / 1$ (normal female range $3-12 \mathrm{nmol} / \mathrm{l}$ ), respectively. An ultrasound scan of the abdomen and pelvis showed normal ovaries, uterus, and right adrenal gland, while the left adrenal gland appeared enlarged. Subsequent computed tomography of the abdomen showed a well circumscribed left adrenal mass $3 \mathrm{~cm}$ by $2 \mathrm{~cm}$ in size.

On the basis of the raised androgen concentrations and scan appearances a left virilising adrenal tumour was diagnosed, and the patient underwent an uneventful ipsilateral adrenalectomy. Histological examination confirmed a well circumscribed, benign, adrenocortical adenoma, while the adjoining zona glomerulosa and reticularis were described as slightly prominent. The histopathology report included a comment that "in light of the clinical features, this is likely to be functional."

Four weeks after surgery the patient's testosterone and androstenedione concentrations remained greatly increased at $9.3 \mathrm{nmol} / 1$ and $51.6 \mathrm{nmol} / 1$, respectively. Selective venous sampling was performed, the results from which suggested that the source of the continuing excessive androgens was the right adrenal gland. Further adrenalectomy was planned, but she was also referred for a full evaluation of her endocrine function. The presence of virilising clinical features was confirmed, although she declined examination of the genitalia, which she said were normal.

Investigations showed that in addition to the raised basal serum testosterone and androstenedione concentrations, basal $17 \alpha$-hydroxyprogesterone concentration was also increased at $16.0 \mathrm{nmol} / 1$ (normal range 1.4-12.0 nmol/1), suggesting congenital adrenal hyperplasia. This was confirmed by administration of dexamethasone $0.5 \mathrm{mg}$ at nighit, which returned the androgen and $17 \alpha$-hydroxyprogesterone concentrations to within the normal ranges. Measurement of 11-deoxycortisol concentration, which was also grossly 